\title{
Tissue engineering the cancer microenvironment-challenges and opportunities
}

\author{
Vassilis Papalazarou ${ }^{1,2} \cdot$ Manuel Salmeron-Sanchez ${ }^{2} \cdot$ Laura M. Machesky $^{1}$ (D) \\ Received: 3 September 2018 / Accepted: 15 October 2018 / Published online: 8 November 2018 \\ (C) The Author(s) 2018
}

\begin{abstract}
Mechanosensing is increasingly recognised as important for tumour progression. Tumours become stiff and the forces that normally balance in the healthy organism break down and become imbalanced, leading to increases in migration, invasion and metastatic dissemination. Here, we review recent advances in our understanding of how extracellular matrix properties, such as stiffness, viscoelasticity and architecture control cell behaviour. In addition, we discuss how the tumour microenvironment can be modelled in vitro, capturing these mechanical aspects, to better understand and develop therapies against tumour spread. We argue that by gaining a better understanding of the microenvironment and the mechanical forces that govern tumour dynamics, we can make advances in combatting cancer dormancy, recurrence and metastasis.
\end{abstract}

Keywords Mechanosensing $\cdot$ Cancer microenvironment $\cdot$ Extracellular matrix $\cdot$ Adhesion $\cdot$ Cell migration $\cdot$ Cytoskeleton $\cdot$ Motility $\cdot$ Hydrogels

\section{Introduction}

One of the biggest challenges in the treatment of cancer is to develop better ways to predict, detect and eradicate the spread of tumour cells to distant tissues. Cancer cells interact dynamically with their surrounding environment and not only remodel the nearby extracellular matrix but also affect immune cell infiltration, local fibroblasts and distant tissues. Pancreatic ductal adenocarcinoma (PDAC) provides an example of a cancer that is characterised by aggression fuelled by the microenvironment. PDAC tumours are often highly fibrotic with excessive deposition of extracellular matrix (ECM) molecules, including fibrillar collagen. Excess matrix deposition not only contributes to the aggressiveness of the malignancy

Electronic supplementary material The online version of this article (https://doi.org/10.1007/s12551-018-0466-8) contains supplementary material, which is available to authorized users.

Laura M. Machesky

L.machesky@beatson.gla.ac.uk

1 CRUK Beatson Institute for Cancer Research and Institute of cancer Sciences, University of Glasgow, Garscube Campus, Switchback Road, Bearsden, Glasgow G61 1BD, UK

2 The Centre for the Cellular Microenvironment, University of Glasgow, Glasgow G12 8QQ, UK but also poses major constraints on the delivery of chemotherapeutic reagents to the tumour (Kleeff et al. 2016). This socalled desmoplastic, collagen-rich stroma has been the target of recent therapeutic intervention strategies, with attempts to 'normalise' the stroma to allow better access of chemotherapy or immunotherapy, reviewed in (Vennin et al. 2018). However, the role of this dense matrix is complex and it remains poorly understood which stromal aspects prevent or promote tumorigenesis. Unfortunately, attempts to ablate the matrix have so far not led to patient benefit and may even cause harm (reviewed in (Neesse et al. 2015)). We will explore how recent developments in bioengineering might improve modelling the interactions between tumour cells and the microenvironment to hopefully improve development of new therapies against metastasis and recurrence (Table 1).

Epithelial tumours are a complex mixture of cancer cells, normal cells and extracellular matrix. Tumours disrupt organ structure and break the normal rules of organisation, growth control and boundary respect. They harbour fibroblasts and immune cells, as well as their own vasculature and lymphatic vessels. Tumours are inflamed and have been described as wounds that never heal, having lost normal signals that allow tissues to maintain their structural and biological framework (Dvorak 2015). In particular, wound healing is a multiparametric process of stochastic events including cell infiltration, ECM deposition and remodelling, where 
Table 1 Summary of processes affected by mechanical properties of the environment and associated references

\begin{tabular}{|c|c|c|c|}
\hline Mechanical properties & Processes affected & Processes affected & References \\
\hline Stiffness & Mechanosensing & $\begin{array}{l}\text { Yap/Taz, integrin } \\
\text { signalling, RTK } \\
\text { signalling, Wnt } \\
\text { signalling, Piezo, } \\
\text { GTPases }\end{array}$ & $\begin{array}{l}\text { Aragona et al. 2013; } \\
\text { Diamantopoulou et al. } \\
\text { 2017; Dupont et al. 2011; } \\
\text { Halder et al. 2012; Lin } \\
\text { et al. 2015; Panciera et al. } \\
\text { 2017; Zanconato et al. } \\
\text { 2016 }\end{array}$ \\
\hline Viscoelasticity & Mechanosensing & $\begin{array}{l}\text { Yap/Taz, integrin } \\
\text { signalling, } \\
\text { GTPases }\end{array}$ & $\begin{array}{l}\text { Bennett et al. 2018; } \\
\text { Chaudhuri 2017; Chen } \\
\text { et al. 2015; Wang et al. } \\
\text { 2018a, b }\end{array}$ \\
\hline \multicolumn{4}{|l|}{ Architecture } \\
\hline Fibre alignment & $\begin{array}{l}\text { Migration direction cell } \\
\text { density }\end{array}$ & $\begin{array}{l}\text { Actin dynamics, } \\
\text { adhesion }\end{array}$ & $\begin{array}{l}\text { Ahmadzadeh et al. 2017; } \\
\text { Chaudhuri et al. 2014; } \\
\text { Conklin et al. 2018; } \\
\text { Drifka et al. 2016; Fraley } \\
\text { et al. 2015; Mouw et al. } \\
\text { 2014; Nuhn et al. 2018; } \\
\text { Patel et al. 2018; Yang } \\
\text { et al. } 2017\end{array}$ \\
\hline Matrix geometry-pore size & $\begin{array}{l}\text { Nuclear squeezing, } \\
\text { rupture } \\
\text { genomic instability }\end{array}$ & $\begin{array}{l}\text { Nesprin/SUN } \\
\text { proteins } \\
\text { DNA damage }\end{array}$ & $\begin{array}{l}\text { Bennett et al. 2017; Denais } \\
\text { et al. 2016; } \\
\text { Elosegui-Artola et al. } \\
\text { 2017; Harada et al. 2014; } \\
\text { Isermann and } \\
\text { Lammerding 2017; } \\
\text { Lautscham et al. 2015; } \\
\text { Lombardi et al. 2011; } \\
\text { Rothballer et al. 2013; } \\
\text { Wolf et al. 2013; } \\
\text { Woroniuk et al. } 2018\end{array}$ \\
\hline Topography curvature & $\begin{array}{l}\text { Curvature sensing } \\
\text { cytoskeleton/signalling? }\end{array}$ & $\begin{array}{l}\text { BAR domain } \\
\text { proteins }\end{array}$ & $\begin{array}{l}\text { Harada et al. 2014; Chen } \\
\text { et al. 2012; Heath and } \\
\text { Insall } 2008\end{array}$ \\
\hline
\end{tabular}

mechanical regulation restores tissue homeostasis and architecture. However, loss of mechanical checkpoints could facilitate neoplasm generation and growth. In addition, tumour vasculature is tortuous and leaky, giving access to tumour cells and preventing oxygen and nutrient delivery in areas of the tumour. When combined with the excessive mutation rates and genomic instability of cancer cells, the aforementioned parameters can drive tumours to break away from their primary site and metastasise. Thus, a thorough understanding of mechanical forces that organise normal and malignant tissues is essential. We argue that recent advances in bioengineering can make exciting contributions to combatting tumour progression and dissemination by revealing how forces shape tissues and tumours.

While normal tissue development follows an orderly programme, cancer and metastasis are chaotic. During development, stem cells give rise to more differentiated precursors and migration follows orderly programmes. Blood vessels invade tissues and form networks to deliver oxygen and nutrients (Fig. 1). ECM mechanics guide developmental migration, stem cell formation and organogenesis (reviewed in (Kumar et al. 2017)). Physical forces in normal tissues are balanced to maintain identity and architecture (Butler and Wallingford 2017; Gilbert and Weaver 2017; Vijayraghavan and Davidson 2017). During tumorigenesis, aspects of the developmental process can be mimicked, but in a chaotic way (Fig. 1). The balance that maintains normal tissue architecture is lost by overgrowth and inappropriate matrix deposition, leading to increased cell crowding and nutrient starvation. These changes promote migration away from the primary tumour into the extracellular matrix or invasion into the lymph or vascular systems. Cancer cells can also be shed into the imperfect tumour vasculature and gain access to the circulation to disseminate widely. The vast majority of disseminated tumour cells die, either from shear forces in the blood or because they land in a hostile environment. However, if even one cell in a million survives, it can gain the potential to form a new tumour or to lie dormant in a tissue until conditions trigger new tumour formation. Disseminated cells can land in a niche that promotes stem cell characteristics or alternatively 
Embryogenesis- balanced forces guide morphogenesis

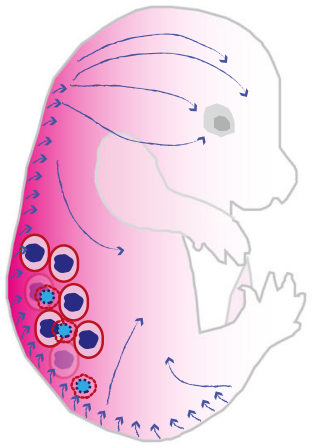

Angiogenesis

Migration (e.g. melanoblasts)

Stem cells and progenitors

(e.g. neural crest)

Programmed cell death

(e.g. apoptosis to form digits)

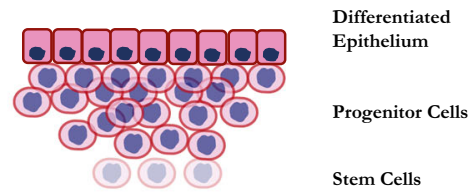

Stem cell niche establishment

Structured epithelial organisation

Tumour growth and metastasis- unbalanced forces drive chaos

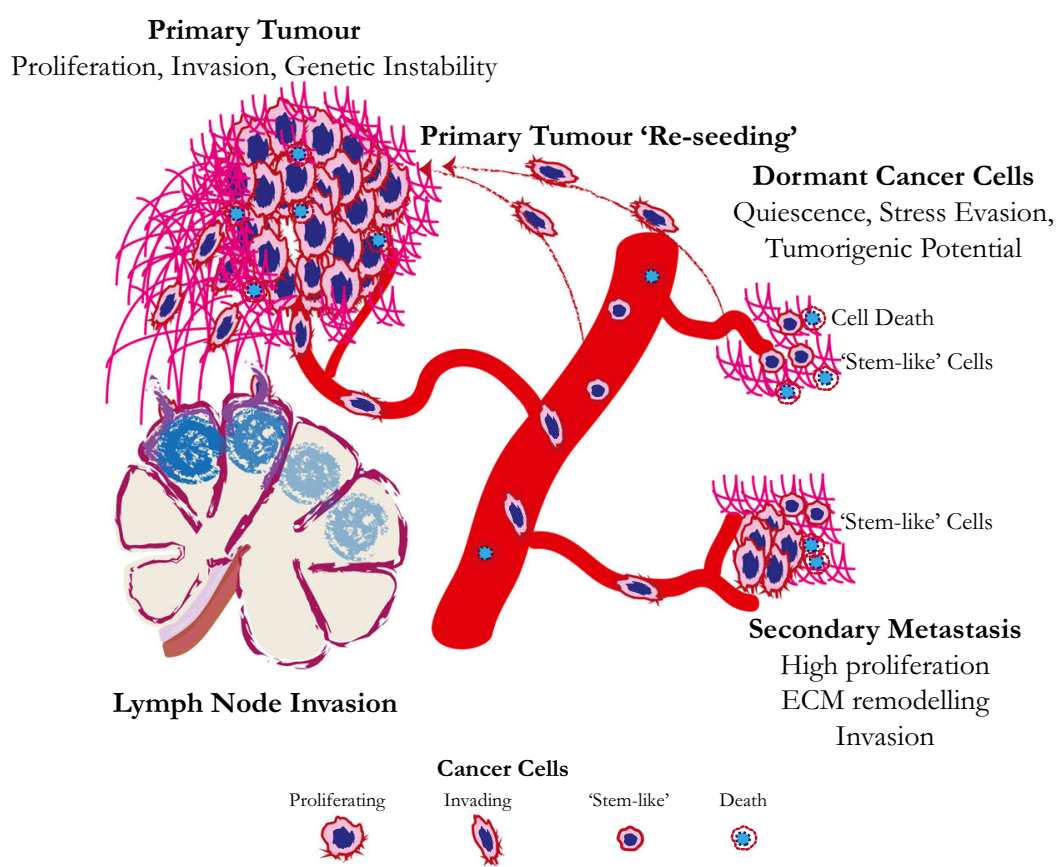

Fig. 1 During embryogenesis, forces balance as cells proliferate, differentiate and sort into specific tissues and organs. Angiogenesis allows oxygenation of the growing embryo and migration, both collectively and individually, drives sorting and homing of cells and tissues. Embryonic tissue shows plasticity in cell fate, but as development progresses, cells become more committed, and stem cells form in specific niches, where they continue to maintain tissues and organism in the adult. Programmed cell death is also important for pruning out cells during sculpting, such as in the formation of digits. The differentiated epithelium (shown right) is an example of a tissue that maintains stem cells in a niche, progenitor cells and differentiated cells in a continuous state of equilibrium in the adult. There is much less cell motility in adult tissues than embryonic, and growth is generally balanced by death and pruning. Unlike the well-organised embryo, tumours behave in more unpredictable and chaotic ways. However, in common with embryos, they show increased angiogenesis and cell migration. The blood vessels in tumours are generally leaky and tortuous, resulting

make their way back and colonise in the primary tumour and thus increase its heterogeneity and aggressiveness (Kim et al. 2009) (Fig. 1). from and causing further force imbalances. Tumours also have stemlike cells and have altered capacity for proliferation, often hyperproliferating or suppressing programmed cell death to become crowded and deprived of nutrients. If the stem-like cells escape from the primary tumour, they may land in lymph nodes or travel through the bloodstream, where they can seed new tumours (metastases) at distant sites. Most escaping tumour cells are thought to die due to the hostile conditions and the body's surveillance system, but if even a few survive, they can start new tumours. New tumour formation can start immediately or after years of dormancy, a poorly understood state where the cells lie in the host tissue, but the tumour is not detectable. Dormancy may be quiescence and fails to grow, or may be a balance of growth and death that keeps the small cluster undetectable. However, these small micrometastases re-awaken and can result in full metastasis. Metastases can also shed cells into the bloodstream that return to the primary tumour and increase its aggressiveness and diversity

This review will focus on how mechanical constraints or imbalances, imposed by the extracellular matrix and cell crowding of malignant tissues, shape cell behaviour and drive 
tumour progression and metastasis. We will also discuss how biophysical methods and engineered environments could provide reliable in vitro platforms to measure mechanical force imbalances and determine their consequences for cancer cell behaviour. We highlight the need for a comprehensive biophysical approach to better understand the interactions between the cancer cells and their environment, ultimately facilitating the design of novel and effective therapeutic strategies.

\section{ECM mechanical properties-I. Rigidity sensing governs proliferation, migration and identity}

Normal cells display anchorage-dependence, a process by which cells sense adhesion to the ECM via transmembrane receptors, especially integrins, which signal to the nucleus to regulate proliferation and survival. Integrins bind to ECM ligands, such as fibronectin or collagen, mainly through their arginyl-glycyl-aspartic acid (RGD) motifs. Binding and tension against the substratum cause integrins to undergo a conformational change promoting their activation and clustering, triggering adhesion and proliferation (Schwartz 2010). The controlled presentation of ECM molecules on normal epithelial tissues can maintain and regulate the homeostasis of tissue growth and architecture. However, during tumorigenesis, extensive ECM remodelling and deposition of a different repertoire of ECM molecules by cancer cells and cancer-associated fibroblasts perturb this balance. Furthermore, genetic changes in the tumour cells, frequently leading to increased Ras and MAP kinase signalling, render them anchorage-independent (Kang and Krauss 1996). Strikingly, Ras GTPases can also activate integrin-dependent signalling cascades in an adhesion independent manner, a process known as 'inside-out' integrin activation (reviewed in (Kinbara et al. 2003), see Fig. 2). All of these changes impact on control of proliferation and survival, allowing cancer cells to override signals from a hostile environment designed to eliminate them.

Integrin adhesions not only control proliferation but also motility, via direct connections with the actin cytoskeleton. Vinculin and talin are mechanosensitive proteins that couple actin to integrins at focal adhesions. They form what is termed a molecular clutch (Fig. 3) whereby actin polymerises and is pushed and pulled back from the plasma membrane toward the cell centre by myosin-II in a phenomenon known as retrograde flow. When the clutch is engaged on a rigid substratum, the actin tethers to the focal adhesions and force is generated to drive motility. When cells are on a softer substratum, the clutch is less engaged and adhesions are weakerpreventing accumulation of the tension that drives forward translocation of the cell. In particular, talin can be periodically stretched in an actin flow dependent manner, revealing cryptic vinculin-binding sites on the talin molecule (del Rio et al.
2009; Wang 2007). Rigidity sensing is mediated by a series of cytoskeletal-dependent contraction forces on the edge of the cells (Iskratsch et al. 2014). Essentially, it seems that cells sense their underneath matrix by contracting it through a series of sequential events involving actin polymerisation and focal complex assembly and reinforcement. How cells sense and respond to stiffness is still a very active area of study, and a recent screen for receptor tyrosine kinases (RTKs) involvement implicated Axl and ROR2 phosphorylating tropomyosin 2.1, myosin IIA and filamin A (Prager-Khoutorsky et al. 2011; Yang et al. 2016). These signalling pathways provide a direct connection between the cytoskeleton and RTKs in mechanosensing, which could have broad implications for cancer if they turn out to be general.

Do cancer cells sense rigidity? Or have they lost this control? A recent study demonstrates that some cancer cells can maintain high proliferation rates even on low adhesion environments (Yang et al. 2018). However, physical and chemical gradients in the tumour microenvironment are crucial for tumour progression (Oudin and Weaver 2016) suggesting that transformed cells still sense and respond to ECM rigidity. Tumours not only secrete more matrix than normal tissues, but they remodel it differently, leading to increased stiffness, breach of basement membrane barriers and hypoxia. Different types of collagens, fibronectin, tenascins and other ECM molecules are abundant in the microenvironment of tumours (for examples, see Box 1); these contribute to the alteration of ECM mechanical properties. In addition, tumour ECM becomes infiltrated by immune cells and fibroblasts, which deposit ECM as well as increasing crowding, pressure and nutrient consumption. Both tumour cells and surrounding cancer-associated fibroblasts (CAFs) show enhanced expression of the collagen crosslinking catalyst lysyl oxidase (LOX) (Erler et al. 2006; Erler and Giaccia 2006; Miller et al. 2015). Collagen crosslinking increases ECM stiffness and promotes invasion and cancer malignancy (Levental et al. 2009). LOX expression may also increase in the pre-metastatic niche leading to changes that promote survival or growth of metastases (Erler et al. 2009). Furthermore, it has been suggested that Caveolin-1 expression by CAFs increases ECM stiffness in the tumour microenvironment promoting cell invasion. Caveolin-1 can control the phosphorylation of the RhoGAP p190, an important regulator of Rho GTPase activity. This results in defective contractility and increased invasiveness of fibroblasts but also to the deposition of an altered highly crosslinked collagen matrix (Goetz et al. 2011). Together, these increase tumour ECM stiffness, a property that is currently emerging as one of the most important biophysical manifestations of the tumour microenvironment.

ECM stiffness promotes matrix remodelling and invasion via signalling pathways such as FAK-dependent activation of Rac1 (Bae et al. 2014; Charras and Sahai 2014). Cancer cells respond to increased stiffness by assembling invadopodia, 


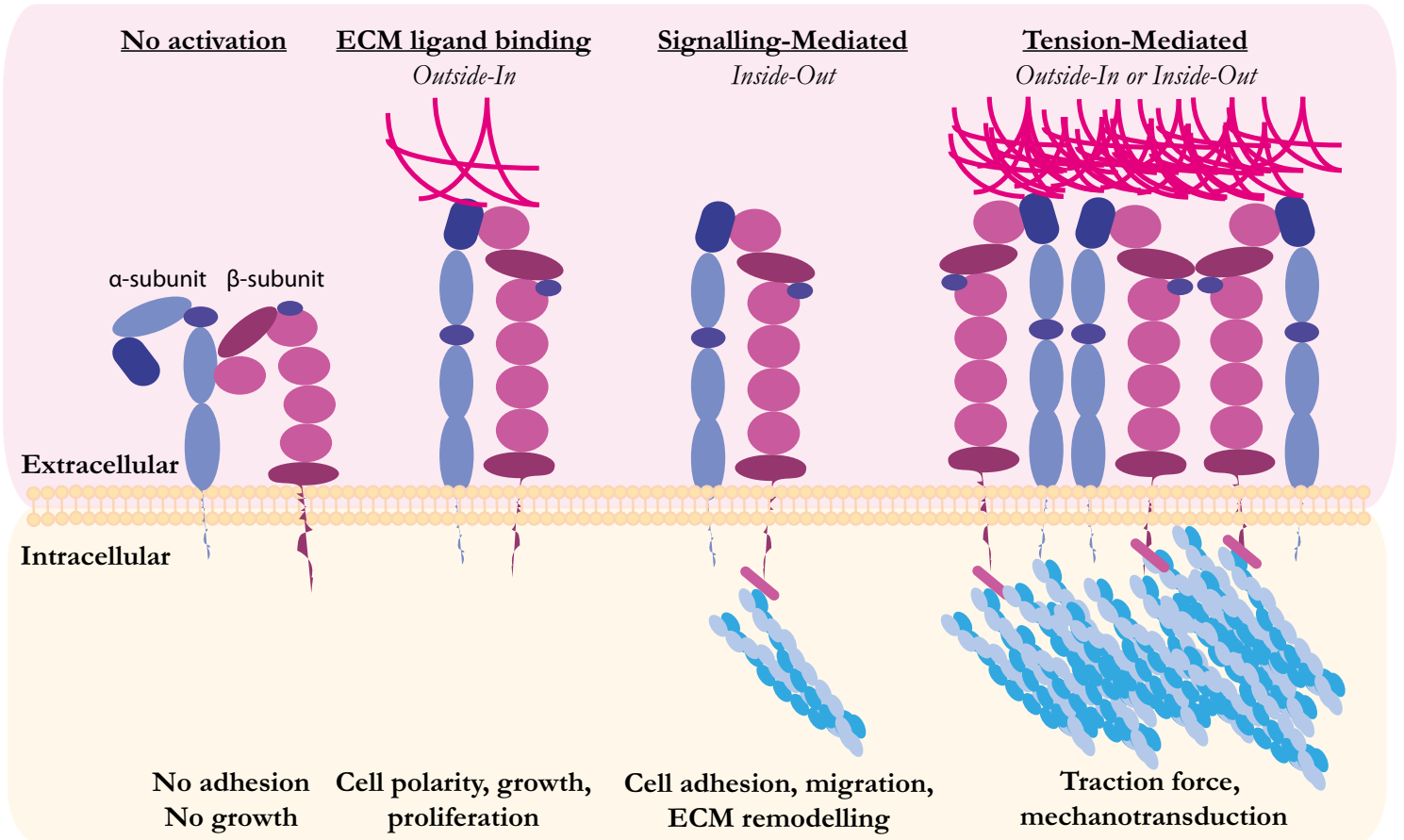

Fig. 2 Integrin activation and importance for balanced growth. Integrins lie at the roots of cellular mechanosensing, as they are considered to be the main membrane receptors mediating cell-ECM interactions. They are heterodimers of $\alpha$ - and $\beta$-subunits forming an elongated extracellular ligand binding domain and a short cytoplasmic tail. In the absence of stimuli, integrin subunits have an inactive bent conformation. Integrin subunit elongation and activation can occur either through ECM protein ligand binding on the extracellular site ('outside-in') or by intracellular signalling events mediated mainly by focal complex or actin cytoskeleton associated protein such as talin ('inside-out'). Integrin activity can enhance remodelling of the surrounding microenvironment which can also promote more integrin activation indicating a positive loop.

actin-rich structures that not only exert force on the matrix but also engage matrix metalloproteases, which degrade ECM (Eddy et al. 2017; Haage and Schneider 2014; Yu et al. 2012). Invadopodia and actin-based protrusions are important mediators of invasion and metastatic spread of pancreatic tumours in vivo ( $\mathrm{Li}$ et al. 2014). In pancreatic tumours with SMAD4 mutations, ECM stiffness was linked to high STAT3 signalling activity inducing increased tension and fibrosis, favouring an aggressive phenotype (Laklai et al. 2016). Furthermore, ECM stiffness can promote angiogenesis, altering normal vasculature integrity to mimic cancer-associated vasculature (Bordeleau et al. 2017).

ECM stiffness impacts on gene expression signatures in both normal and tumour tissues, enhancing programmes that determine cell identity and differentiation or stemness. ECM stiffness is linked to induction of epithelial-to-mesenchymal transition (EMT), a developmental process that goes awry in cancer and is linked to progression of epithelial cancers such as PDAC (Krebs et al. 2017; Morris and Machesky 2015). Specifically, Twistl is a critical transcriptional regulator that acts as an EMT promoter and is regulated by increased ECM
Tension and mechanical force arising either from ECM or cytoskeletal dynamics can also extend, activate and cluster integrin subunits. Nontransformed cells require a degree of ECM adhesion and integrin signalling to sustain their proliferation and growth. Malignant transformation, however, maintains cell proliferation even in the absence of ECM adhesion. At the same time though, transformed cells display integrin enrichment and imbalanced cell-ECM dynamics. Tumours frequently display an increase in ECM stiffness, which can be further enhanced by inflammation and fibrosis. This can drive increased cytoskeletal activation as well as signalling downstream of integrin activation

stiffness, favouring invasion and metastasis (Wei et al. 2015). In addition to integrin-actin connections, the nucleus is coupled with adhesions and actin to cause transcriptional changes that regulate many tumour-promoting processes. The nuclear translocation of two transcriptional co-factors, Yap and Taz, mediates transcriptional responses to ECM mechanosensing in many cells and tissues (Panciera et al. 2017). Yap/Taz and the transcriptional factor TEAD are part of the well-known Hippo pathway, an evolutionarily conserved developmental pathway that controls tissue morphogenesis and homeostasis (Panciera et al. 2017).

ECM rigidity triggers integrin clutch engagement and leads to nuclear translocation and activation of YAP/Taz signalling (Halder et al. 2012). In the absence of mechanical stress, Yap/ Taz are localised to the cytoplasm where they can be phosphorylated by LATS1 and turned over in the proteasome (Panciera et al. 2017). Activation of Yap/Taz signalling triggers a transcriptional programme that affects cell stemness and differentiation (Lian et al. 2010). Multiple targets downstream of Yap/Taz are affected by mechanosensing, including the matricellular matrix protein $\mathrm{CCN} 1$, which promotes cancer 


\section{Low ECM force}

(Clutch un-engaged)
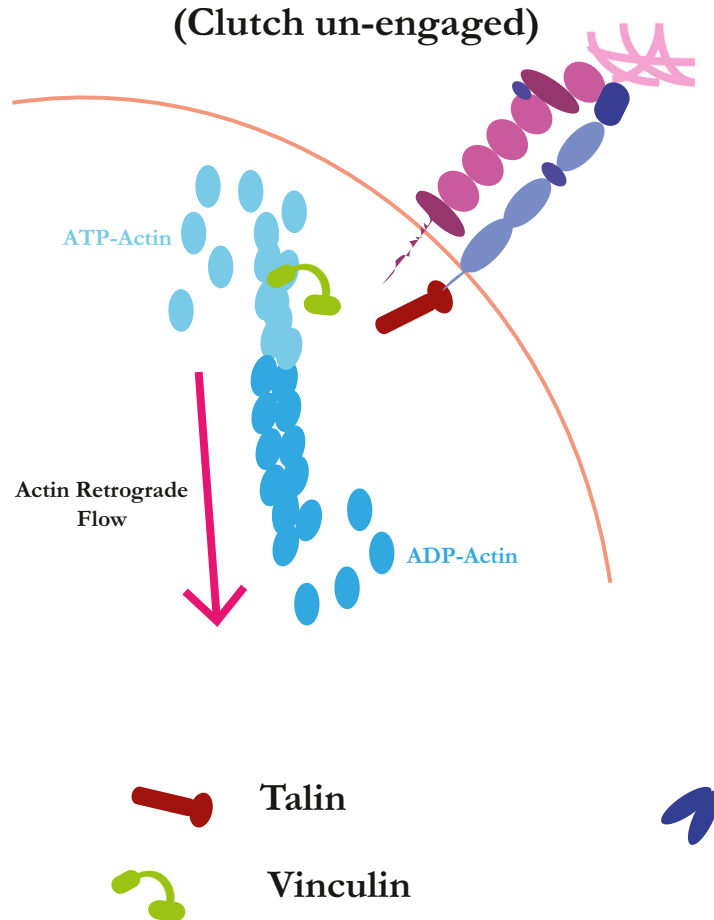

Fig. 3 Cells generate force against stiff ECM, leading to clutch engagement. When cells experience soft or viscous matrix, where adhesions do not generate enough tension to stretch mechanosensitive proteins and trigger a response, the molecular clutch remains unengaged. In this situation, actin polymerisation at the leading edge is uncoupled from adhesion, and retrograde flow of newly generated filaments occurs in the direction away from the plasma membrane. Adhesions remain small, and the cell is not able to use actin-based protrusion to move against the substratum. However, upon a threshold

cell intravasation and metastasis (Reid et al. 2017). Another transcriptional regulator FHL2 (four-and-a-half LIM domain family protein 2) translocates to the nucleus on soft substrates, where it induces the transcription of $\mathrm{p} 21$, negatively regulating cell proliferation (Nakazawa et al. 2016). While mechanosensitive transcriptional targets are beginning to be uncovered, much more needs to be done to fully understand how mechanosensing impacts on cell identity and differentiation. Furthermore, although some actin regulators have been implicated in Yap/Taz connection to the cytoskeleton (Aragona et al. 2013), the connections between Yap/Taz and the molecular clutch warrant further investigation.

The nucleus is physically connected with the cytoplasm and is under stress in normal cells. Disruption of this connection affects its size and shape with important implications for genome function (Mazumder and Shivashankar 2010). In particular, the nucleus is coupled to the actin cytoskeleton and focal complexes via nesprins and the nuclear LINC complex (Lombardi et al. 2011). The LINC complex consists of nesprins, KASH and SUN proteins that span the nuclear

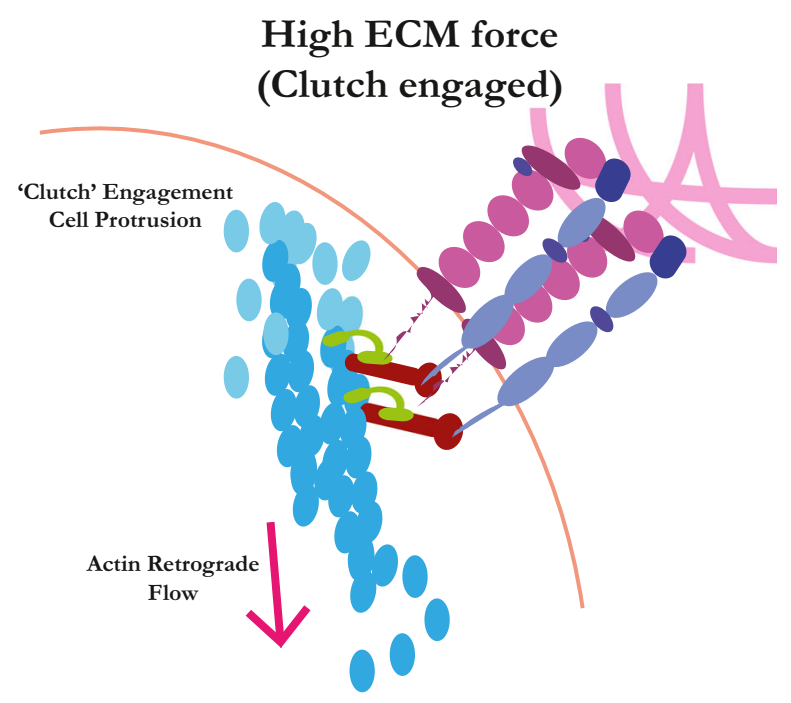

Myosin

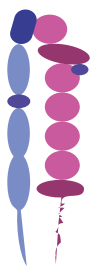

Integrins

of ECM stiffness, mechanosensitive cytoskeletal linkers, such as vinculin and talin, engage and form a molecular clutch. The clutch catches the ECM-derived force and transmits it to the cytoskeletal cortex. As adhesions increase in size due to integrin clustering and the cytoskeleton couples to the rigid matrix, actin polymerisation results in membrane protrusion and promotes motility. During tumorigenesis, high ECM stiffness, enrichment and hyperactivation, the mechanosensing machinery can promote invasion, migration and metastatic dissemination

membrane and interact both with chromatin and the actin cytoskeleton (Rothballer et al. 2013) (Fig. 4). The LINC complex regulates cell cycle progression in response to stress, for example in Drosophila melanogaster muscle (Wang et al. 2018a). In addition to transmitting force to chromatin, ECM stiffness couples with nuclear pores, exposing their interiors to the cytoplasm and thus triggering active nuclear import. This is thought to work by causing captured protein targets, including YAP, to unfold and be imported from the cytoplasm (Elosegui-Artola et al. 2017). Mechanisms of this increased import are still unknown, but perhaps nuclear softening, due to altered expression of lamins, could further enhance mechanosensitivity.

One of the most direct ways that cell mechanosense is via ion channels. Ion channels are pore-forming transmembrane proteins that control the flow of ions across the cell membrane. They can be rapidly influenced by ECM derived force or pressure, regulating a variety of cell behaviours. Specifically, the Piezo channel is a massive 38-transmembrane spanning channel that translates mechanical stimuli into calcium signals 


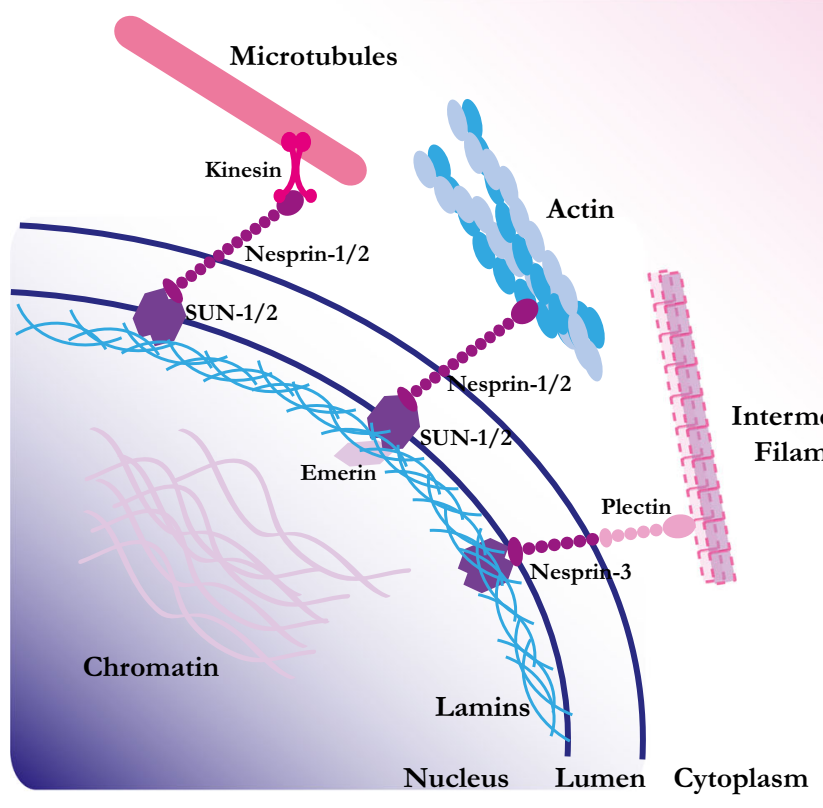

Fig. 4 Nuclear forces are balanced by the cytoskeleton. The nucleus is connected to the cytoskeleton via transmembrane proteins, including nesprins and SUN proteins. These assemblies are called the LINC, linker of the nucleoskeleton and cytoskeleton complex. The LINC complex connects to the cytoskeleton, including actin filaments, microtubules and intermediate filaments through the nuclear envelope to chromatin. The LINC complex is usually composed by the SUN protein subunits connected to lamins intranuclearly and the nesprin

(Wang et al. 2018b; Zhao et al. 2018). Piezo is important for stem cell mechanosensing in the Drosophila midgut, mediating proliferation and differentiation (He et al. 2018), as well as for touch sensation in neurons (Ranade et al. 2014; Woo et al. 2015). When cells crawl through a confined space, Piezo is activated to increase intracellular calcium levels, leading to negative regulation of protein kinase-A (Hung et al. 2016). This pathway works in concert with myosin-II to sense confinement and regulate cell migration, as well as setting up a positive feedback of myosin-II-activated calcium influx (Hung et al. 2016). Piezo is implicated in pressure-induced pancreatitis, a form of pancreatic inflammation resulting from trauma, duct obstruction or any medical procedure that puts pressure on the pancreas (Romac et al. 2018). Inhibiting Piezo can reduce pancreatitis, suggesting potential for therapy and perhaps scope for further exploring a role of Piezo channels in pancreatic cancer. Considering also the deregulated calcium signalling that cancer cells exhibit and that targeting calcium signalling emerges as a potential cancer therapy (Cui et al. 2017), elucidating how ECM stiffness is communicated within the cancer cells by ion channels will be crucial to understand promotion and dissemination of malignancy.

Among their multiple functions, Rho-family GTPases emerge as major signal transducers of ECM stiffness sensation. In particular, RhoA is one of the most important actomyosin regulators, and Rac1 mediates new actin assembly

\section{Balanced ECM force}

Epithelial polarity, regulated growth optimal cytoplasm/nucleus ratio

\section{Unbalanced ECM force}

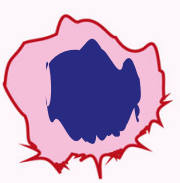

Irregular growth, stretching of nuclear pores, altered gene expression

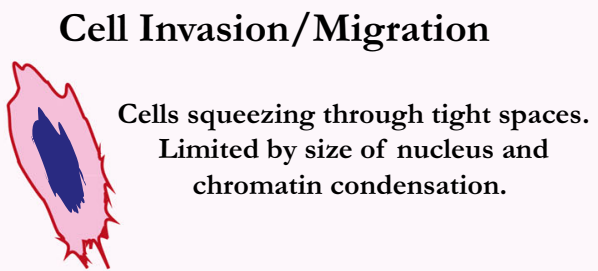

proteins on the cytoplasm. This complex is thought to relay cytoskeletal changes to alterations in chromatin organisation and affect gene expression. Additionally, increased force can lead to stretching of nuclear pores and increased exchange of proteins between the nucleus and the cytoplasm. When cells invade through pores of the ECM or intravasate into a blood vessel and travel through the bloodstream; the associated squeezing and shear forces affect chromatin organisation and stability of the genome

stimulating a plethora of downstream events. Piezo activation causes RhoA activation in response to mechanosensing in cancer cells (Pardo-Pastor et al. 2018). In addition, the RhoGEF obscurin mediates RhoA activation in breast cancer in response to increased ECM stiffness (Stroka et al. 2017). STEF/TIAM2 RacGEF mediates Rac activity in concert with NMMIIB to maintain the cell's perinuclear actin cap (Woroniuk et al. 2018). The perinuclear actin cap is an actinomyosin structure connecting the nucleus to the actin cytoskeleton via nesprin and SUN proteins (Chambliss et al. 2013). Mechanical stimulus triggers the actin cap to relay signals to the Yap/Taz pathway as well as maintaining nuclear structure and orientation during migration (Diamantopoulou et al. 2017). Considering the multiparametric role of GTPases in cancer progression, it will be worth investigating how the aforementioned pathways are affected by ECM-derived force in tumorigenesis.

\section{Modelling stiffness in vitro}

The first and still most commonly used materials to recapitulate the ECM of tumours in vitro are natural ECM-derived components, including fibronectin, collagen, cell-derived matrices or reconstituted basement membranes. Their major advantages over artificially generated systems are their intrinsic biocompatibility and cell adhesion properties. However, there 
is a need to engineer surfaces that not only mimic biomechanical properties of the ECM but also offer the option to control dynamics, degradability and protein composition, while maintaining other properties. Standard 2D systems for probing the mechanoresponsiveness of cells have included either PDMS (polydimethylsiloxane) surfaces or hydrogels usually composed by acrylamide. The latter can be mechanically tuned by varying the crosslinker concentration to modulate the stiffness and incorporate RGD adhesive peptides to facilitate cell adhesion (Kandow et al. 2007). Alginate (a polysaccharide derived from algae) and reconstituted basement membrane are also materials that can be incorporated into a synthetic interpenetrating polymer network. Their stiffness can be modulated by altering the ionic crosslinking of alginate, without changing other parameters including polymer concentration (Chaudhuri et al. 2014). Recent innovations allow the production of controllable synthetic hydrogels that support organoid and cancer spheroid growth. These offer exciting opportunities for studying cell behaviour in 3D allowing complex cellular co-cultures and defined physical properties (Cruz-Acuna and Garcia 2017). Polyethylene glycol (PEG) and poly(lactide-co-glycolide) (PLG) are commonly used to control mechanical properties in 3D hydrogels. They are often engineered to incorporate cell adhesion ligands as well as biodegradable crosslinkers to increase bio- and cyto-compatibility. The stiffness of those synthetic 3D hydrogels can be varied by changing the length and density of crosslinkers and have already been applied to studies of cancer cell properties, including growth, invasion and migration (Singh et al. 2015) (Fig. 5). Not only stiffness but also composition is important. It is worth noting that complex $3 \mathrm{D}$ systems require precise characterisation to identify the exact properties that the encapsulated cells sense. In addition, cells interact dynamically with their milieu, an interaction that includes degradation, secretion and deposition of extracellular molecules (Ferreira et al. 2018)

Since ECM stiffness changes dynamically through extensive remodelling and protein deposition, it is important to generate smarter materials that will allow us to study how cells respond to dynamic, periodic or reversible alterations of the mechanical properties. Classic synthetic hydrogels are irreversibly remodelled by cells, and their mechanical properties usually cannot be tuned after their generation. However, recent chemical developments allow novel material applications to engineer 3D microenvironments that can be rapidly and reversibly modified in a controllable manner-reviewed in (Rosales and Anseth 2016). For example, the use of photoswitchable crosslinkers has allowed stiffening of a synthetic hydrogel upon light stimulus (Frey and Wang 2009; Guvendiren and Burdick 2012; Lee et al. 2018; Yeh et al. 2017). Enzymic reactions have also been recently applied to mediate stiffening of hydrogels in situ (Liu et al. 2017). Thus, it is now possible to dynamically assess cancer cell responses to acute and local changes of the stiffness of their environment in controlled conditions. This could be especially relevant in the pre-metastatic niche, where immune cell activity, wounding or trauma might trigger awakening of dormant cancer cells and promote metastatic growth.

\section{ECM mechanical properties-II. Viscosity has a similar role to rigidity, but is relatively unexplored}

\section{Viscoelasticity of the tumour matrix is an understudied relative of stiffness}

While stiffness is an established driver of biological mechanosensing, the importance of viscosity and viscoelasticity of the ECM is just beginning to be understood. Elastography on human patients showed malignant breast tumours to be more viscous or fluid-like than benign lesions, suggesting physiological relevance (Sinkus et al. 2007). In addition, interstitial fluid in the tumour niche might contribute to the viscous properties of the ECM. Viscosity engages the molecular clutch in much the same way as stiffness does, and triggers adhesion assembly and Yap/Taz signalling (Bennett et al. 2018). Changing matrix composition, including differential expression of collagens, laminins and fibronectin, as well as accumulation of hyaluronan and other viscous ECM components will create an altered viscosity in the tumour microenvironment. Hyaluronan accumulation, for example, correlates with increased cancer stemness and aggressiveness of tumours (Chanmee et al. 2016a, b). Further research is needed to unravel the contribution of those viscous properties on tumour progression. Matrix viscoelasticity impacts proliferation and cell spreading by mechanisms that are not yet understood (Bauer et al. 2017; Chaudhuri et al. 2015). Identifying the liquid/solid states of desmoplastic tumours, such as pancreatic ductal adenocarcinoma, could open up new therapeutic possibilities.

Not only ECM viscosity, but viscosity of the tissue at the level of cell-cell interactions, governs normal and cancer cell organisation. Tumours contain masses of tightly packed cells, which have been described as physically jammed. It is mechanically challenging for packed cells forming cell-cell junctions to flow past each other or move freely. This has been modelled in vitro using cell monolayers, which are fluid during low confluency, but then jammed as the cells proliferate continuously and pack more tightly in a confined space (Chepizhko et al. 2018). Upregulation of endocytic trafficking can un-jam epithelial cancer cells, promoting flow and collective movement. In particular, the small GTPase Rab5a, an important mediator of endocytosis, induces collective cell motility upon physical constraints and jammed monolayers, a process that is interrupted by increasing fluid efflux 
a

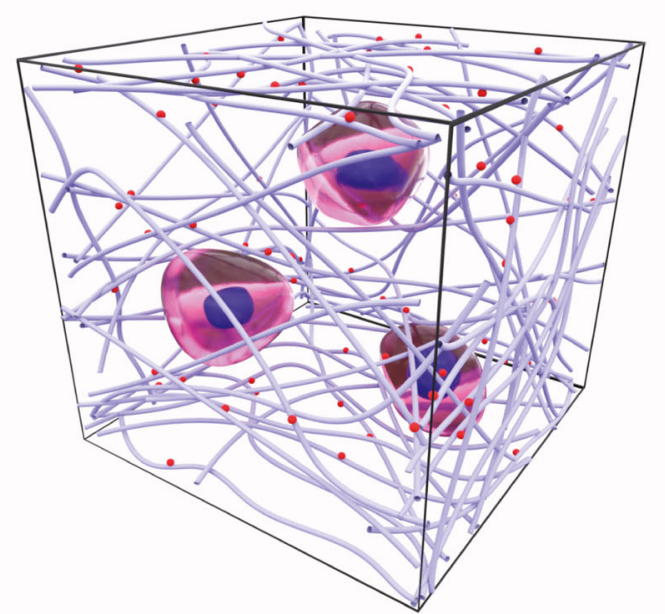

b

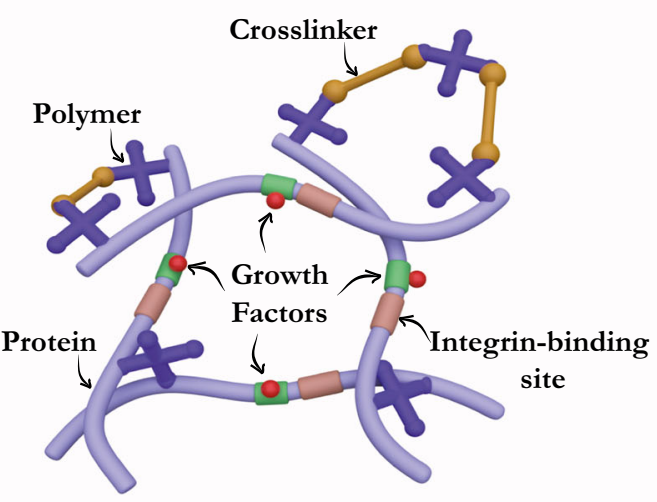

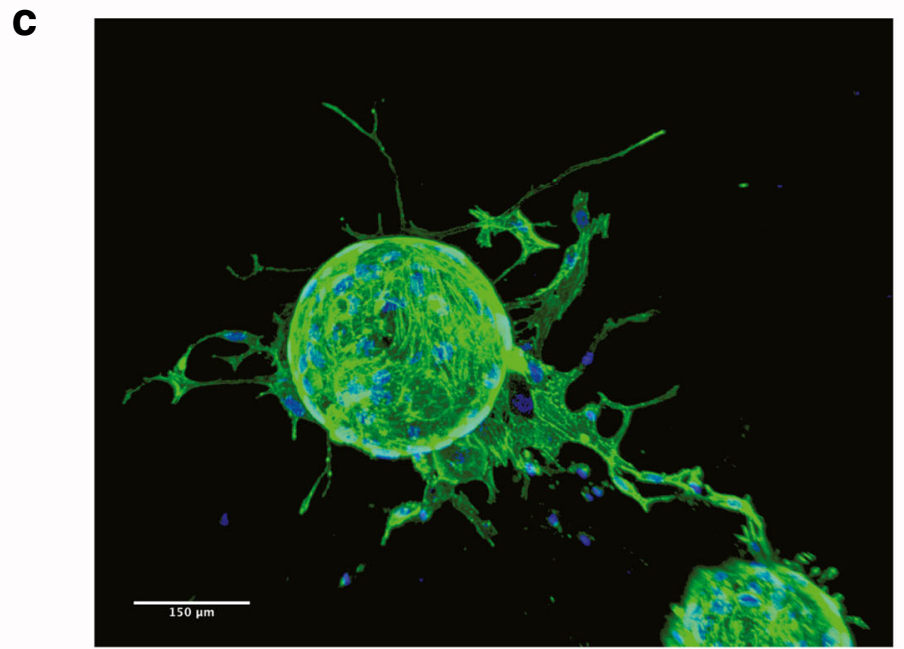

Fig. 5 Hydrogels recapitulate mechanical aspects of the microenvironment. a Sketch of a hydrogel, showing cells embedded in the 3D environment. b Details of an example hydrogel, showing crosslinker, which can be varied to control pore size and stiffness; polymer, which can also be varied to change mechanical and chemical properties; protein, which can represent an endogenous tissue or tumour

(Malinverno et al. 2017). In addition, E-cadherin trafficking is thought to play a major role in unjamming cells (Song et al. 2013). Many tumours still express E-cadherin, and its mobility correlates with metastatic potential (Erami et al. 2016). Cancer predominantly invades in a collective manner, and thus it will be important to study the viscosity of invasion streams and surrounding matrix to inform about likelihood of metastasis or response to treatments.

\section{Modelling viscoelasticity in vitro}

Various models are in development to model ECM viscoelasticity. Engineered lipid bilayers can be manipulated to present different cellular stress relaxation properties (Bennett et al. matrix protein such as fibronectin; growth factor, which can be included in the hydrogel and presented either upon stimulus or constitutively. $\mathbf{c}$ Micrograph showing spheroid of mouse pancreatic cancer cells growing in a hydrogel. Sketches courtesy of Sara Trujillo-Munoz, University of Glasgow

2018). Interestingly, it is also possible to generate hydrogels of constant stiffness but of variable viscoelasticity. This is achieved by modifying the molecular weight of the crosslinkers and therefore their mobility (reviewed in (Chaudhuri 2017)). It would thus be possible to test whether dynamic-mechanical phenomena (e.g. stress relaxation) could trigger awakening of dormant cancer cells or affect invasive capabilities. This new idea bears testing, as tissues and tumours are differently viscoelastic in nature, and their properties change over relevant timescales. For example, when the lungs inflate and deflate, shear stress is created and even small changes in viscosity may lead to increased epithelial damage (Chen et al. 2015). This damage could activate an increased stretch response in dormant cells, as well as causing local 
inflammation and thus affecting recurrence of lung cancer or lung metastases of other cancers.

A key study from Shenoy and colleagues highlights the most relevant parameters to consider for modelling the importance of viscosity on cell spreading. These are the timescales for binding of the molecular clutch, the lifetime of engagement of the molecular motors and the substrate relaxation times (Gong et al. 2018). Only by comparing the timescales of cellular events with substrate relaxation events can we reveal the impact of viscoelastic properties on cell behaviour. These authors concluded that for soft substrates, there was an optimal viscosity with characteristic relaxation time that slows down the response to cell pulling and stiffens the material and thus promotes cell spreading. In contrast, on rigid substrates, viscosity made little difference to cell engagement since the bound clutches are already saturated by stiffness. Importantly, this study used three different types of hydrogels to demonstrate these effects, including hyaluronic acid, alginate and polyacrylamide, with biological matrix molecules such as collagen incorporated. They also used different cell types to show robustness at the biological level and supported their conclusions with a Monte-Carlo model. Another recent study used encapsulation of deformable high molecular weight long linear polyacrylamide within crosslinked polyacrylamide hydrogels to have independent control of elasticity and viscosity and model soft tissues (Charrier et al. 2018). Use of these new materials revealed that differentiation of hepatic stellate cells could be dependent on viscosity, showing a relevance of viscosity in biological processes. Further development of tuneable viscosity hydrogels will enable a thorough study of viscosity.

Tightly packed cells such as in epithelial monolayers have been compared with particles in a tightly packed suspension, which can jam when the temperature is low, the density is high and the suspension acquires a yield stress. Cell-cell viscosity in jammed epithelia has been mathematically modelled, and although this is still a relatively new idea, studying the jamming transitions using models developed for physical systems may be applicable to biological systems (Gamboa Castro et al. 2016). Cells of mesenchymal or epithelial phenotype were mixed together in varying densities. Velocity was measured as a function of density, which revealed that motility arrest occurred in certain conditions and could be modelled similar to jamming in physical systems. However, another study of cell jamming argues that cellular contraction and adhesion are key components of motility behaviour that are overlooked in such models, challenging therefore the idea that cells behave like particles in a suspension (Vig et al. 2017). More studies are needed to determine the usefulness of the various analogies and models.

Recent developments in tissue decellularization techniques allowed the isolation of various native ECM environments from whole organs and subsequent study of viscoelastic properties. In particular, in situ decellularization of tissues (ISDoT) not only allows decellularization of whole organs but also seems to leave ECM architecture intact (Mayorca-Guiliani et al. 2017). That allowed proteomic mapping of the ECM components and could also facilitate correlation of such profiles with viscoelastic mechanics of different ECM environments including for example premetastatic and metastatic niches. Study of decellularized tissues could also promote the design of more intricate ECMmimicking materials. Such advances could reveal the contributions of ECM viscoelastic properties to tumour progression.

\section{ECM architecture-I. Density, linearity and alignment govern migration and cell identity}

\section{Matrix fibre alignment reinforces migration patterns and enhances stiffness signals}

In addition to stiffness, tumour matrix displays abnormal architecture: typically, fibres align radially away from the centre of tumours and are frequently bundled into highways traversed by cells at the invasive edges (Han et al. 2016; Sander 2014). Fibre alignment promotes invasive behaviour and has been modelled using collagen gels (Ahmadzadeh et al. 2017; Fraley et al. 2015). Additionally, collagen alignment has been correlated to alpha-SMA expression indicating a transformation of normal residing pancreatic fibroblasts, known as stellate cells, toward cancer-associated fibroblasts (Drifka et al. 2016). Thus, both tumour and stromal cells are transformed to a more aggressive phenotype by fibre alignment. Fibre alignment not only affects migration but also may contribute to hypoxia at the centre of tumours, setting up a self-reinforcing pro-metastatic programme. High-density collagen hydrogels triggered cancer cells to migrate and degrade their surrounding matrix when they were under hypoxic conditions (Lewis et al. 2017). Hypoxia promotes changes in composition and remodelling of the ECM. The hypoxia-inducible factor 1 (HIF-1) alters ECM deposition and remodelling genes to promote fibre alignment, stiffening and further intensifying hypoxia (Gilkes et al. 2013). A correlation between collagen architecture and hypoxic areas has also been reported in vivo (Kakkad et al. 2010). Interestingly, alignment of collagen fibres is correlated with reduced survival in a cohort of 114 PDAC patients (Drifka et al. 2016). It is worth exploring whether fibre alignment additionally might set up barriers to chemotherapy and immune therapy and exploring how immune cells react to the radially aligned tumour matrix. 


\section{Modelling fibre alignment in vitro}

Collagen is one of the most commonly used biopolymers to study $3 \mathrm{D}$ cell behaviour in vitro. The study of collagen architecture has been facilitated by the development of advanced optical techniques, including second-harmonic generation (SHG) microscopy (Vennin et al. 2018) which takes advantage of the helical arrangement of collagen (see Box 1) to image scattered photons. SHG imaging of human tumours, combined with other stromal markers, associated collagen ECM architecture with PDAC progression (Drifka et al. 2016). Another promising method, liquid crystal-based polarised light imaging, provides label-free imaging of collagen fibre orientation and alignment (Keikhosravi et al. 2017). Collagen matrix alignment can be performed, and cell migration was studied in vitro using methods such as rotational $3 \mathrm{D}$ alignment of collagen fibres (Nuhn et al. 2018) and reviewed in (Wolf et al. 2009). Self-assembling 3D collagen matrices engineered with the crosslinking enzyme transglutaminase II have been informative of the role of matrix alignment and topography to MMP activity in cell migration (Fraley et al. 2015). The stiffness of $3 \mathrm{D}$ collagen gels can be controlled using glycation, a monosaccharide-dependent modification of collagen residues. This modification can increase the rigidity of the gels without affecting architecture (Bordeleau et al. 2017; Nuhn et al. 2018). Fibre alignment can be accompanied by another change, with impact on bone metastasis and mineralisation. The latter is essentially a composition of type I collagen fibrils with intrafibrillar crystals of non-stoichiometric carbonated hydroxyapatite. A polymer-induced liquid-precursor (PILP) process has been applied to mimic intrafibrillar collagen mineralisation in vitro, demonstrating that collagen mineralisation can increase cell motility (Choi et al. 2018). Some PDAC tumours show mineralisation, but this has not, to our knowledge, been correlated with fibre arrangement or invasiveness and may be interesting for future study.

While reconstitution of collagen matrix provides important insights, synthetic fibres offer increased control of mechanical properties and alignment on nano-, mesoand micro-scales. Electrospinning, a method whereby an electrical field is used to draw viscoelastic polymer solutions out of a reservoir and by electrical repulsion, causes them to jet into a thin filament that is a longstanding technique to generate fibres of controlled composition, alignment and physical properties (Pham et al. 2006). Recently, electrospun fibres have been combined with native ECM proteins, such as laminin and collagen (Kwon et al. 2017), to reconstitute 3-dimensional scaffolds for cells and tissues. By manipulating the alignment of electrospun fibres, it is possible to recapitulate in vivo architecture, such as those found in wounds (radial) or tendons (uniaxial) (Pham et al. 2006). An alternative to electrospinning is flow spinning, where a fluid reservoir draws out the jets of viscoelastic polymers into fibres with various dimensions and topology (Madurga et al. 2017). The fibres are aligned onto substrates of desired dimension in the centre of the well. This method avoids high voltages and may be more biocompatible.

\section{ECM architecture-II. Geometry: Confinement and topography}

\section{Matrix geometry influences migration and tumour progression}

Curvature is another important consideration of ECM, as cells contain curvature sensing proteins, and, for example, nanopitpatterned surfaces decrease cell adhesion compared to flat substrates (Martines et al. 2004). The BAR domain comprises a curved protein domain that self-assembles and can sense curvature or induce curvature in membrane surfaces (Chen et al. 2012). Bar proteins interact with small GTPases, such as Rac1, and can influence signalling, cytoskeletal architecture and membrane dynamics (reviewed in (Vogel and Sheetz 2006)). BAR domain-containing proteins also generate curvature on endocytic membranes, and they can possibly drive formation of filopodia and lamellipodia, structures that trigger cell motility and dissemination of cancer cells (Heath and Insall 2008). Some BAR proteins are upregulated or mutated in cancer and have been implicated in EMT (Chen et al. 2012). BAR proteins also contribute to the invasiveness of cancer cells, promoting invadopodia formation (Pichot et al. 2010; Yamamoto et al. 2011). In addition to BAR proteins, the nuclear LINC complex is implicated in curvature sensing, via transmission of stretch when a cell is on a convex surface. When tested on cell-sized nano-pits, cells positioned themselves into concave pits where the nucleus was under the least tension (Pieuchot et al. 2018; Werner et al. 2017). It is intriguing to ask whether membrane curvature alterations might also contribute to the reawakening of quiescent or dormant tumour cells.

Related to curvature is pore size, another important property of ECM that varies widely in vivo and in cancer. ECM porosity in particular has been studied extensively in relation to cell migration (reviewed in (Charras and Sahai 2014)). Development of a 3D cell culture system uncoupling collagen concentration from collagen gel microarchitecture indicated that cancer cells acquired a more motile and invasive phenotype when exposed to small pores (Carey et al. 2012). Migration through small pores has been linked to DNA damage and genomic instability (reviewed in (Isermann and Lammerding 2017)). A migrating cell can squeeze through 
very small openings, sometimes down to a few microns in diameter, but is limited by how much it can compact its nucleus. Extreme nuclear compaction can damage the nuclear envelope inducing increased exchange between cytoplasmic and nuclear proteins (Denais et al. 2016). To overcome limited ECM pore size, cancer cells can employ proteolytic activity and ECM degradation (Wolf et al. 2013). Not only are pores limiting, but nuclear squeezing during migration can lead to rupture and increased genomic instability. For example, cytoplasmic nucleases could enter into the nucleus causing DNA damage (Irianto et al. 2017). In addition, normal cells have mechanisms to repair nuclear envelope rupture (Olmos et al. 2015, 2016; Vietri et al. 2015), such as the endosomal sorting complexes required for transport (ESCRT) machinery (Isermann and Lammerding 2017). Defects in the repair of nuclear envelope ruptures during migration through restricted ECM pores could further contribute to cancer aggressiveness. Since the nucleus is mechanically coupled to the actin cytoskeleton (Fig. 4), it is also vulnerable to the forces transmitted through it. There is evidence that ECM stiffness increases genome instability (Pfeifer et al. 2017). DNA damage caused by migration through constricted pores can hinder the proliferation of cancer cell lines (Pfeifer et al. 2018). It is not yet clear how significant the effect of matrix geometry is on DNA damage in vivo, as other factors (e.g. DNA repair mechanisms) also play a major role.

Interestingly, ECM geometry and confinement can also regulate signalling pathways, including YAP signalling. Cell confinement and spreading can induce Yap nuclear translocation (Dupont et al. 2011), as can stretching or inducing curvature to a confluent monolayer (Aragona et al. 2013), with mechanical stress being transmitted through cell-cell junctions (Benham-Pyle et al. 2015). Thus, it seems that the curvature and the topography of the ECM could be important regulators of YAP activity in cancer. Apart from the confinement of cancer cells or proteins, ECM nano- and micro-conformation could also confine diffusible factors in limited spaces. These could signal to cancer cells and trigger chemotactic responses with important implications to cancer spread (Tweedy et al. 2016).

\section{Modelling ECM topography in vitro}

When trying to model ECM topography, an important challenge is how to uncouple it from intrinsic mechanical properties, such as viscoelasticity. Carey et al. recently presented an improved collagen gel culture system, where collagen porosity could be studied independently from concentration (Carey et al. 2012). In addition, semi-3D microfabricated substrates have been applied to mimic confined microenvironments (Booth-Gauthier et al. 2013). 3D microchannel scaffolds of collagen and glycosaminoglycan have been used to model ECM porosity to study fibroblast migration (Harley et al.
2008). Microfluidic devices are useful to study cell migration in conditions that could mimic cell crawling inside the tissues in vitro (Irimia et al. 2007). Recent advances include the incorporation of native decellularized tissue ECM into tissue matrix scaffolds to fabricate porous hydrogel systems with tissue-like architectural integrity (Rijal and Li 2017). Synthetic porous hydrogels can also be generated using a variety of methods, including PEG cryogels (Dispinar et al. 2012), electrospinning of fibres (Kwon et al. 2017; Matthews et al. 2002; Pham et al. 2006) or alginate hydrogels with engineered microcavities (Zeng et al. 2014). 3D PEG hydrogels fabricated with micro- or macro-pores have been useful to study angiogenesis and vascularisation (Dziubla and Lowman 2004; Oliviero et al. 2012). PEG chains can also be used as porogens to generate hydrogel membranes with controlled permeabilities (Decock et al. 2018).

It will be desirable to develop materials with reversible or dynamically altered properties. This might be facilitated by the development of controllable porogens or by the use of nano- or micro-patterned silk fibres (Xiao et al. 2018) that could mimic native tissue architecture. In particular, engineering ECM topography would be facilitated by recent advances in 3D bioprinting. For example, direct ink writing allows to combine hydrogels, ECM components and cells into complex 'tissue-mimicking' constructs on a layer by layer fashion even in the absence of scaffolds (reviewed in ( $\mathrm{Ji}$ and Guvendiren 2017)). Such systems are currently used to study stem cell differentiation with evident applications in regenerative medicine (Gopinathan and Noh 2018), but incorporating malignant ECM along with stromal or cancer cells in such structures would significantly enhance our palette of tools for understanding the role of ECM in cancer. Further technical developments as well as the incorporation of bioinks derived from different ECM environments such as decellularized tissues (Choudhury et al. 2018) would rapidly improve our control of the architecture, mechanics and biology of fabricated materials, in a precise and reproducible way, paving the way to the design and development of reliable 'organ-' or even 'tumour-'on-a-chip approaches.

\section{Outlook for the future and translation}

Tumorigenesis destabilises normal tissue architecture and thus throws forces in the affected tissue out of balance. Gaining a full understanding of how the different physical and biological aspects of the ECM control cancer cell behaviour, from genome integrity to motility and invasion, will be informative for appreciating what delineates metastatic disease and dormancy. To achieve this formidable task, better tools need to be developed not only to monitor and visualise ECM properties in vivo but also to precisely and controllably model them in vitro. Elastography, a method to image collagen density shows great promise for identifying tissue stiffness in 
biopsies, correlating to disease stage. This has been further expanded to assess viscoelastic properties (Sinkus et al. 2007). However, further progress is required to increase imaging quality and to apply more sophisticated image analysis algorithms to stratify patients and hopefully to predict metastatic spread or disease recurrence. To further understand the involvement of ECM in cancer progression and in the control of quiescent versus proliferative properties of tumour cells, engineered materials with controlled properties, on a reversible and independent manner, are required. This might be facilitated by the use of novel chemicals and the incorporation of full-length native ECM-derived proteins. These could act as scaffolds to present different growth factors or diffusible chemical signals to cells, on a controllable or stress-related way. Fibronectin, for example, has the ability to bind growth factors such as TGF- $\beta$ or BMP- 2 and keep them in a latent form to be presented to cells (Grigoriou et al. 2017). Controllable stretching or degradation of these growth factor-bound fibres might not only change the mechanical properties but also causes release of signalling molecules causing them to present to cells in a physiologically relevant way.

The ultimate aim is to identify therapies that could target cancer cells using an efficient and holistic approach. Understanding which aspects facilitate or restrict cancer spread, how dormant tumorigenic cells are awakened and what are the requirements for successful seeding of a distant secondary tissue will contribute to therapeutic developments. Since chemotherapeutic agents must diffuse into the ECM to access the tumour bulk, ECM topography, confinement and vascularisation are important aspects to consider when designing and testing new agents. Novel engineered microenvironments will prove useful for drug screening allowing more physiologic tests of drug efficiency.

ECM mechanics play key roles in a variety of diseases, so cross-disease studies may offer new insights, such as correlating the effects of fibrosis or arthritis and cancer. It seems that reshaping of the cancer ECM along with common chemotherapeutic strategies might provide promise in the future (Vennin et al. 2018). However, elucidating further how ECM mechanics and architecture shape malignancy will expand both our understanding and therapeutic tools against malignancy.

\section{Compliance with ethical standards}

Funding information LMM acknowledges funding from the Cancer research UK Core grant A15673 and a CRUK centre studentship to VP.

Conflict of interest Vassilis Papalazarou declares that he has no conflict of interest. Manuel Salmeron-Sanchez declares that he has no conflict of interest. Laura M. Machesky declares that she has no conflict of interest.

Ethical approval This article does not contain any studies with human participants or animals performed by any of the authors.
Open Access This article is distributed under the terms of the Creative Commons Attribution 4.0 International License (http:// creativecommons.org/licenses/by/4.0/), which permits unrestricted use, distribution, and reproduction in any medium, provided you give appropriate credit to the original author(s) and the source, provide a link to the Creative Commons license, and indicate if changes were made.

\section{References}

Ahmadzadeh H, Webster MR, Behera R, Jimenez Valencia AM, Wirtz D, Weeraratna AT, Shenoy VB (2017) Modeling the two-way feedback between contractility and matrix realignment reveals a nonlinear mode of cancer cell invasion. Proc Natl Acad Sci U S A 114: E1617-E1626. https://doi.org/10.1073/pnas.1617037114

Aragona M et al (2013) A mechanical checkpoint controls multicellular growth through YAP/TAZ regulation by actin-processing factors. Cell 154:1047-1059. https://doi.org/10.1016/j.cell.2013.07.042

Bae YH et al (2014) A FAK-Cas-Rac-lamellipodin signaling module transduces extracellular matrix stiffness into mechanosensitive cell cycling. Sci Signal 7:ra57. https://doi.org/10.1126/scisignal. 2004838

Bauer A, Gu L, Kwee B, Li WA, Dellacherie M, Celiz AD, Mooney DJ (2017) Hydrogel substrate stress-relaxation regulates the spreading and proliferation of mouse myoblasts. Acta Biomater 62:82-90. https://doi.org/10.1016/j.actbio.2017.08.041

Benham-Pyle BW, Pruitt BL, Nelson WJ (2015) Cell adhesion. Mechanical strain induces E-cadherin-dependent Yap1 and betacatenin activation to drive cell cycle entry. Science 348:10241027. https://doi.org/10.1126/science.aaa4559

Bennett RR, Pfeifer CR, Irianto J, Xia Y, Discher DE, Liu AJ (2017) Elastic-Fluid Model for DNA Damage and Mutation from Nuclear Fluid Segregation Due to Cell Migration. Biophys J 112:22712279. https://doi.org/10.1016/j.bpj.2017.04.037

Bennett M, Cantini M, Reboud J, Cooper JM, Roca-Cusachs P, Salmeron-Sanchez M (2018) Molecular clutch drives cell response to surface viscosity. Proc Natl Acad Sci U S A 115:1192-1197. https://doi.org/10.1073/pnas.1710653115

Booth-Gauthier EA, Du V, Ghibaudo M, Rape AD, Dahl KN, Ladoux B (2013) Hutchinson-Gilford progeria syndrome alters nuclear shape and reduces cell motility in three dimensional model substrates. Integr Biol (Camb) 5:569-577. https://doi.org/10.1039/c3ib20231c

Bordeleau F et al (2017) Matrix stiffening promotes a tumor vasculature phenotype. Proc Natl Acad Sci U S A 114:492-497. https://doi.org/ 10.1073/pnas.1613855114

Butler MT, Wallingford JB (2017) Planar cell polarity in development and disease. Nat Rev Mol Cell Biol 18:375-388. https://doi.org/10. 1038/nrm.2017.11

Carey SP, Kraning-Rush CM, Williams RM, Reinhart-King CA (2012) Biophysical control of invasive tumor cell behavior by extracellular matrix microarchitecture. Biomaterials 33:4157-4165. https://doi. org/10.1016/j.biomaterials.2012.02.029

Chambliss AB, Khatau SB, Erdenberger N, Robinson DK, Hodzic D, Longmore GD, Wirtz D (2013) The LINC-anchored actin cap connects the extracellular milieu to the nucleus for ultrafast mechanotransduction. Sci Rep 3:1087. https://doi.org/10.1038/ srep01087

Chanmee T, Ontong P, Itano N (2016a) Hyaluronan: a modulator of the tumor microenvironment. Cancer Lett 375:20-30. https://doi.org/ 10.1016/j.canlet.2016.02.031

Chanmee T et al (2016b) Hyaluronan production regulates metabolic and cancer stem-like properties of breast cancer cells via hexosamine biosynthetic pathway-coupled HIF-1 signaling. J Biol Chem 291: 24105-24120. https://doi.org/10.1074/jbc.M116.751263 
Charras G, Sahai E (2014) Physical influences of the extracellular environment on cell migration. Nat Rev Mol Cell Biol 15:813-824. https://doi.org/10.1038/nrm3897

Charrier EE, Pogoda K, Wells RG, Janmey PA (2018) Control of cell morphology and differentiation by substrates with independently tunable elasticity and viscous dissipation. Nat Commun 9:449. https://doi.org/10.1038/s41467-018-02906-9

Chaudhuri O (2017) Viscoelastic hydrogels for 3D cell culture. Biomater Sci 5:1480-1490. https://doi.org/10.1039/c7bm00261k

Chaudhuri O, Koshy ST, Branco da Cunha C, Shin JW, Verbeke CS, Allison KH, Mooney DJ (2014) Extracellular matrix stiffness and composition jointly regulate the induction of malignant phenotypes in mammary epithelium. Nat Mater 13:970-978. https://doi.org/10. 1038/nmat4009

Chaudhuri O et al (2015) Substrate stress relaxation regulates cell spreading. Nat Commun 6:6364. https://doi.org/10.1038/ncomms7365

Chen Y, Aardema J, Misra A, Corey SJ (2012) BAR proteins in cancer and blood disorders. Int J Biochem Mol Biol 3:198-208

Chen ZL, Song YL, Hu ZY, Zhang S, Chen YZ (2015) An estimation of mechanical stress on alveolar walls during repetitive alveolar reopening and closure. J Appl Physiol (1985) 119:190-201. https://doi.org/10.1152/japplphysiol.00112.2015

Chepizhko O, Lionetti MC, Malinverno C, Giampietro C, Scita G, Zapperi S, La Porta CAM (2018) From jamming to collective cell migration through a boundary induced transition. Soft Matter 14: 3774-3782. https://doi.org/10.1039/c8sm00128f

Choi S, Friedrichs J, Song YH, Werner C, Estroff LA, Fischbach C (2018) Intrafibrillar, bone-mimetic collagen mineralization regulates breast cancer cell adhesion and migration. Biomaterials. https://doi. org/10.1016/j.biomaterials.2018.05.002

Choudhury D, Tun HW, Wang T, Naing MW (2018) Organ-derived decellularized extracellular matrix: a game changer for bioink manufacturing? Trends Biotechnol 36:787-805. https://doi.org/10. 1016/j.tibtech.2018.03.003

Conklin MW et al (2018) Collagen alignment as a predictor of recurrence after ductal carcinoma in situ. Cancer Epidemiol Biomarkers Prev 27:138-145. https://doi.org/10.1158/1055-9965.EPI-17-0720

Cruz-Acuna R, Garcia AJ (2017) Synthetic hydrogels mimicking basement membrane matrices to promote cell-matrix interactions. Matrix Biol 57-58:324-333. https://doi.org/10.1016/j.matbio.2016.06.002

Cui C, Merritt R, Fu L, Pan Z (2017) Targeting calcium signaling in cancer therapy. Acta Pharm Sin B 7:3-17. https://doi.org/10.1016/ j.apsb.2016.11.001

Decock J, Schlenk M, Salmon JB (2018) In situ photo-patterning of pressure-resistant hydrogel membranes with controlled permeabilities in PEGDA microfluidic channels. Lab Chip 18:1075-1083. https://doi.org/10.1039/c7lc01342f

del Rio A, Perez-Jimenez R, Liu R, Roca-Cusachs P, Fernandez JM, Sheetz MP (2009) Stretching single talin rod molecules activates vinculin binding. Science 323:638-641. https://doi.org/10.1126/ science. 1162912

Denais CM et al (2016) Nuclear envelope rupture and repair during cancer cell migration. Science 352:353-358. https://doi.org/10.1126/ science.aad7297

Diamantopoulou Z et al (2017) TIAM1 antagonizes TAZ/YAP both in the destruction complex in the cytoplasm and in the nucleus to inhibit invasion of intestinal. Epithelial Cells Cancer Cell 31:621-634 e626. https://doi.org/10.1016/j.ccell.2017.03.007

Dispinar T, Van Camp W, De Cock LJ, De Geest BG, Du Prez FE (2012) Redox-responsive degradable PEG cryogels as potential cell scaffolds in tissue engineering. Macromol Biosci 12:383-394. https:// doi.org/10.1002/mabi.201100396

Drifka CR et al (2016) Highly aligned stromal collagen is a negative prognostic factor following pancreatic ductal adenocarcinoma resection. Oncotarget 7:76197-76213. https://doi.org/10.18632/ oncotarget.12772
Dupont S et al (2011) Role of YAP/TAZ in mechanotransduction. Nature 474:179-183. https://doi.org/10.1038/nature10137

Dvorak HF (2015) Tumors: wounds that do not heal-redux. Cancer Immunol Res 3:1-11. https://doi.org/10.1158/2326-6066.CIR-140209

Dziubla TD, Lowman AM (2004) Vascularization of PEG-grafted macroporous hydrogel sponges: a three-dimensional in vitro angiogenesis model using human microvascular endothelial cells. J Biomed Mater Res A 68:603-614. https://doi.org/10.1002/jbm.a. 20023

Eddy RJ, Weidmann MD, Sharma VP, Condeelis JS (2017) Tumor cell invadopodia: invasive protrusions that orchestrate metastasis. Trends Cell Biol 27:595-607. https://doi.org/10.1016/j.tcb.2017. 03.003

Elosegui-Artola A et al (2017) Force triggers YAP nuclear entry by regulating transport across. Nuclear Pores Cell 171:1397-1410 e1314. https://doi.org/10.1016/j.cell.2017.10.008

Erami $\mathrm{Z}$ et al (2016) Intravital FRAP imaging using an E-cadherin-GFP mouse reveals disease- and drug-dependent dynamic regulation of cell-cell junctions in live tissue. Cell Rep 14:152-167. https://doi. org/10.1016/j.celrep.2015.12.020

Erler JT, Giaccia AJ (2006) Lysyl oxidase mediates hypoxic control of metastasis. Cancer Res 66:10238-10241. https://doi.org/10.1158/ 0008-5472.CAN-06-3197

Erler JT et al (2006) Lysyl oxidase is essential for hypoxia-induced metastasis. Nature 440:1222-1226. https://doi.org/10.1038/ nature 04695

Erler JT et al (2009) Hypoxia-induced lysyl oxidase is a critical mediator of bone marrow cell recruitment to form the premetastatic niche. Cancer Cell 15:35-44. https://doi.org/10.1016/j.ccr.2008.11.012

Ferreira SA et al (2018) Bi-directional cell-pericellular matrix interactions direct stem cell fate. Nat Commun 9:4049. https://doi.org/10.1038/ s41467-018-06183-4

Fraley SI, Wu PH, He L, Feng Y, Krisnamurthy R, Longmore GD, Wirtz D (2015) Three-dimensional matrix fiber alignment modulates cell migration and MT1-MMP utility by spatially and temporally directing protrusions. Sci Rep 5:14580. https://doi.org/10.1038/ srep14580

Frey MT, Wang YL (2009) A photo-modulatable material for probing cellular responses to substrate rigidity. Soft Matter 5:1918-1924. https://doi.org/10.1039/b818104g

Gamboa Castro M, Leggett SE, Wong IY (2016) Clustering and jamming in epithelial-mesenchymal co-cultures. Soft Matter 12:8327-8337. https://doi.org/10.1039/c6sm01287f

Gilbert PM, Weaver VM (2017) Cellular adaptation to biomechanical stress across length scales in tissue homeostasis and disease. Semin Cell Dev Biol 67:141-152. https://doi.org/10.1016/j. semcdb.2016.09.004

Gilkes DM, Bajpai S, Chaturvedi P, Wirtz D, Semenza GL (2013) Hypoxia-inducible factor 1 (HIF-1) promotes extracellular matrix remodeling under hypoxic conditions by inducing P4HA1, P4HA2, and PLOD2 expression in fibroblasts. J Biol Chem 288: 10819-10829. https://doi.org/10.1074/jbc.M112.442939

Goetz JG et al (2011) Biomechanical remodeling of the microenvironment by stromal caveolin-1 favors tumor invasion and metastasis. Cell 146:148-163. https://doi.org/10.1016/j.cell.2011.05.040

Gong Z et al (2018) Matching material and cellular timescales maximizes cell spreading on viscoelastic substrates. Proc Natl Acad Sci U S A 115:E2686-E2695. https://doi.org/10.1073/pnas.1716620115

Gopinathan J, Noh I (2018) Recent trends in bioinks for 3D printing. Biomater Res 22:11. https://doi.org/10.1186/s40824-018-0122-1

Grigoriou E, Cantini M, Dalby MJ, Petersen A, Salmeron-Sanchez M (2017) Cell migration on material-driven fibronectin microenvironments. Biomater Sci 5:1326-1333. https://doi.org/10.1039/ c7bm00333a 
Guvendiren M, Burdick JA (2012) Stiffening hydrogels to probe shortand long-term cellular responses to dynamic mechanics. Nat Commun 3:792. https://doi.org/10.1038/ncomms 1792

Haage A, Schneider IC (2014) Cellular contractility and extracellular matrix stiffness regulate matrix metalloproteinase activity in pancreatic cancer cells. FASEB J 28:3589-3599. https://doi.org/10.1096/fj. $13-245613$

Halder G, Dupont S, Piccolo S (2012) Transduction of mechanical and cytoskeletal cues by YAP and TAZ. Nat Rev Mol Cell Biol 13:591600. https://doi.org/10.1038/nrm3416

Han W et al (2016) Oriented collagen fibers direct tumor cell intravasation. Proc Natl Acad Sci U S A 113:11208-11213. https://doi.org/10.1073/pnas.1610347113

Harada T et al (2014) Nuclear lamin stiffness is a barrier to 3D migration, but softness can limit survival. J Cell Biol 204:669-682. https://doi. org $/ 10.1083 /$ jcb. 201308029

Harley BA, Kim HD, Zaman MH, Yannas IV, Lauffenburger DA, Gibson LJ (2008) Microarchitecture of three-dimensional scaffolds influences cell migration behavior via junction interactions. Biophys $\mathrm{J}$ 95:4013-4024. https://doi.org/10.1529/biophysj.107.122598

He L, Si G, Huang J, Samuel ADT, Perrimon N (2018) Mechanical regulation of stem-cell differentiation by the stretch-activated Piezo channel. Nature 555:103-106. https://doi.org/10.1038/ nature 25744

Heath RJ, Insall RH (2008) F-BAR domains: multifunctional regulators of membrane curvature. J Cell Sci 121:1951-1954. https://doi.org/ $10.1242 /$ jcs. 023895

Hung WC et al (2016) Confinement sensing and signal optimization via Piezo1/PKA and myosin II pathways. Cell Rep 15:1430-1441. https://doi.org/10.1016/j.celrep.2016.04.035

Irianto J, Xia Y, Pfeifer CR, Greenberg RA, Discher DE (2017) As a nucleus enters a small pore, chromatin stretches and maintains integrity, even with DNA breaks. Biophys J 112:446-449. https://doi. org/10.1016/j.bpj.2016.09.047

Irimia D, Charras G, Agrawal N, Mitchison T, Toner M (2007) Polar stimulation and constrained cell migration in microfluidic channels. Lab Chip 7:1783-1790. https://doi.org/10.1039/b710524j

Isermann P, Lammerding J (2017) Consequences of a tight squeeze: nuclear envelope rupture and repair. Nucleus 8:268-274. https://doi. org/10.1080/19491034.2017.1292191

Iskratsch T, Wolfenson H, Sheetz MP (2014) Appreciating force and shape-the rise of mechanotransduction in cell biology. Nat Rev Mol Cell Biol 15:825-833. https://doi.org/10.1038/nrm3903

Ji S, Guvendiren M (2017) Recent advances in bioink design for 3D bioprinting of tissues and organs. Front Bioeng Biotechnol 5:23. https://doi.org/10.3389/fbioe.2017.00023

Kakkad SM et al (2010) Hypoxic tumor microenvironments reduce collagen I fiber density. Neoplasia 12:608-617

Kandow CE, Georges PC, Janmey PA, Beningo KA (2007) Polyacrylamide hydrogels for cell mechanics: steps toward optimization and alternative uses. Methods Cell Biol 83:29-46. https://doi. org/10.1016/S0091-679X(07)83002-0

Kang JS, Krauss RS (1996) Ras induces anchorage-independent growth by subverting multiple adhesion-regulated cell cycle events. Mol Cell Biol 16:3370-3380

Keikhosravi A, Liu Y, Drifka C, Woo KM, Verma A, Oldenbourg R, Eliceiri KW (2017) Quantification of collagen organization in histopathology samples using liquid crystal based polarization microscopy. Biomed Opt Express 8:4243-4256. https://doi.org/10.1364/ BOE.8.004243

Kim MY, Oskarsson T, Acharyya S, Nguyen DX, Zhang XH, Norton L, Massague J (2009) Tumor self-seeding by circulating cancer cells. Cell 139:1315-1326. https://doi.org/10.1016/j.cell.2009.11.025

Kinbara K, Goldfinger LE, Hansen M, Chou FL, Ginsberg MH (2003) Ras GTPases: integrins' friends or foes? Nat Rev Mol Cell Biol 4: 767-776. https://doi.org/10.1038/nrm1229
Kleeff J et al (2016) Pancreatic cancer. Nat Rev Dis Primers 2:16022. https://doi.org/10.1038/nrdp.2016.22

Krebs AM et al (2017) The EMT-activator Zeb1 is a key factor for cell plasticity and promotes metastasis in pancreatic cancer. Nat Cell Biol 19:518-529. https://doi.org/10.1038/ncb3513

Kumar A, Placone JK, Engler AJ (2017) Understanding the extracellular forces that determine cell fate and maintenance. Development 144: 4261-4270. https://doi.org/10.1242/dev.158469

Kwon GW, Gupta KC, Jung KH, Kang IK (2017) Lamination of microfibrous PLGA fabric by electrospinning a layer of collagenhydroxyapatite composite nanofibers for bone tissue engineering. Biomater Res 21:11. https://doi.org/10.1186/s40824-017-0097-3

Laklai $\mathrm{H}$ et al (2016) Genotype tunes pancreatic ductal adenocarcinoma tissue tension to induce matricellular fibrosis and tumor progression. Nat Med 22:497-505. https://doi.org/10.1038/nm.4082

Lautscham LA et al (2015) Migration in confined 3D environments is determined by a combination of adhesiveness, nuclear volume, contractility, and cell stiffness. Biophys J 109:900-913. https://doi.org/ 10.1016/j.bpj.2015.07.025

Lee IN et al (2018) Photoresponsive hydrogels with photoswitchable mechanical properties allow time-resolved analysis of cellular responses to matrix stiffening. ACS Appl Mater Interfaces 10:77657776. https://doi.org/10.1021/acsami.7b18302

Levental KR et al (2009) Matrix crosslinking forces tumor progression by enhancing integrin signaling. Cell 139:891-906. https://doi.org/10. 1016/j.cell.2009.10.027

Lewis DM, Tang V, Jain N, Isser A, Xia Z, Gerecht S (2017) Collagen fiber architecture regulates hypoxic sarcoma cell migration. ACS Biomater Sci Eng 4:400-409. https://doi.org/10.1021/ acsbiomaterials. $7 \mathrm{~b} 00056$

Li A et al (2014) Fascin is regulated by slug, promotes progression of pancreatic cancer in mice, and is associated with patient outcomes. Gastroenterology 146:1386-1396 e1381-1317. https://doi.org/10. 1053/j.gastro.2014.01.046

Lian I et al (2010) The role of YAP transcription coactivator in regulating stem cell self-renewal and differentiation. Genes Dev 24:11061118. https://doi.org/10.1101/gad.1903310

Lin CH, Pelissier FA, Zhang H, Lakins J, Weaver VM, Park C, LaBarge MA (2015) Microenvironment rigidity modulates responses to the HER2 receptor tyrosine kinase inhibitor lapatinib via YAP and TAZ transcription factors. Mol Biol Cell 26:3946-3953. https://doi.org/ 10.1091/mbc.E15-07-0456

Liu HY, Greene T, Lin TY, Dawes CS, Korc M, Lin CC (2017) Enzymemediated stiffening hydrogels for probing activation of pancreatic stellate cells. Acta Biomater 48:258-269. https://doi.org/10.1016/j. actbio.2016.10.027

Lombardi ML, Jaalouk DE, Shanahan CM, Burke B, Roux KJ, Lammerding J (2011) The interaction between nesprins and sun proteins at the nuclear envelope is critical for force transmission between the nucleus and cytoskeleton. J Biol Chem 286:2674326753. https://doi.org/10.1074/jbc.M111.233700

Madurga R, Ganan-Calvo AM, Plaza GR, Guinea GV, Elices M, PerezRigueiro J (2017) Production of high performance bioinspired silk fibers by straining flow spinning. Biomacromolecules 18:11271133. https://doi.org/10.1021/acs.biomac.6b01757

Malinverno C et al (2017) Endocytic reawakening of motility in jammed epithelia. Nat Mater 16:587-596. https://doi.org/10.1038/nmat4848

Martines E, McGhee K, Wilkinson C, Curtis A (2004) A parallel-plate flow chamber to study initial cell adhesion on a nanofeatured surface. IEEE Trans Nanobioscience 3:90-95

Matthews JA, Wnek GE, Simpson DG, Bowlin GL (2002) Electrospinning of collagen nanofibers. Biomacromolecules 3: 232-238

Mayorca-Guiliani AE, Madsen CD, Cox TR, Horton ER, Venning FA, Erler JT (2017) ISDoT: in situ decellularization of tissues for high- 
resolution imaging and proteomic analysis of native extracellular matrix. Nat Med 23:890-898. https://doi.org/10.1038/nm.4352

Mazumder A, Shivashankar GV (2010) Emergence of a prestressed eukaryotic nucleus during cellular differentiation and development. J R Soc Interface 7(Suppl 3):S321-S330. https://doi.org/10.1098/rsif. 2010.0039.focus

Miller BW et al (2015) Targeting the LOX/hypoxia axis reverses many of the features that make pancreatic cancer deadly: inhibition of LOX abrogates metastasis and enhances drug efficacy. EMBO Mol Med 7:1063-1076. https://doi.org/10.15252/emmm.201404827

Morris HT, Machesky LM (2015) Actin cytoskeletal control during epithelial to mesenchymal transition: focus on the pancreas and intestinal tract. Br J Cancer 112:613-620. https://doi.org/10.1038/bjc. 2014.658

Mouw JK et al (2014) Tissue mechanics modulate microRNA-dependent PTEN expression to regulate malignant progression. Nat Med 20: 360-367. https://doi.org/10.1038/nm.3497

Nakazawa N, Sathe AR, Shivashankar GV, Sheetz MP (2016) Matrix mechanics controls FHL2 movement to the nucleus to activate p21 expression. Proc Natl Acad Sci U S A 113:E6813-E6822. https:// doi.org/10.1073/pnas.1608210113

Neesse A, Algul H, Tuveson DA, Gress TM (2015) Stromal biology and therapy in pancreatic cancer: a changing paradigm. Gut 64:14761484. https://doi.org/10.1136/gutjnl-2015-309304

Nuhn JAM, Perez AM, Schneider IC (2018) Contact guidance diversity in rotationally aligned collagen matrices. Acta Biomater 66:248257. https://doi.org/10.1016/j.actbio.2017.11.039

Oliviero O, Ventre M, Netti PA (2012) Functional porous hydrogels to study angiogenesis under the effect of controlled release of vascular endothelial growth factor. Acta Biomater 8:3294-3301. https://doi. org/10.1016/j.actbio.2012.05.019

Olmos Y, Hodgson L, Mantell J, Verkade P, Carlton JG (2015) ESCRT-III controls nuclear envelope reformation. Nature 522:236-239. https:// doi.org/10.1038/nature14503

Olmos Y, Perdrix-Rosell A, Carlton JG (2016) Membrane binding by CHMP7 coordinates ESCRT-III-dependent nuclear envelope reformation. Curr Biol 26:2635-2641. https://doi.org/10.1016/j.cub. 2016.07.039

Oudin MJ, Weaver VM (2016) Physical and chemical gradients in the tumor microenvironment regulate tumor cell invasion, migration, and metastasis. Cold Spring Harb Symp Quant Biol 81:189-205. https://doi.org/10.1101/sqb.2016.81.030817

Panciera T, Azzolin L, Cordenonsi M, Piccolo S (2017) Mechanobiology of YAP and TAZ in physiology and disease. Nat Rev Mol Cell Biol 18:758-770. https://doi.org/10.1038/nrm.2017.87

Pardo-Pastor C et al (2018) Piezo2 channel regulates RhoA and actin cytoskeleton to promote cell mechanobiological responses. Proc Natl Acad Sci U S A 115:1925-1930. https://doi.org/10.1073/ pnas. 1718177115

Patel A et al (2018) Hierarchically aligned fibrous hydrogel films through microfluidic self-assembly of graphene and polysaccharides. Biotechnol Bioeng. https://doi.org/10.1002/bit.26801

Pfeifer CR, Alvey CM, Irianto J, Discher DE (2017) Genome variation across cancers scales with tissue stiffness - an invasion-mutation mechanism and implications for immune cell infiltration. Curr Opin Syst Biol 2:103-114. https://doi.org/10.1016/j.coisb.2017.04. 005

Pfeifer CR et al (2018) Constricted migration increases DNA damage and independently represses cell cycle. Mol Biol Cell mbcE18020079. https://doi.org/10.1091/mbc.E18-02-0079

Pham QP, Sharma U, Mikos AG (2006) Electrospinning of polymeric nanofibers for tissue engineering applications: a review. Tissue Eng 12:1197-1211. https://doi.org/10.1089/ten.2006.12.1197

Pichot CS et al (2010) Cdc42-interacting protein 4 promotes breast cancer cell invasion and formation of invadopodia through activation of $\mathrm{N}$ -
WASp. Cancer Res 70:8347-8356. https://doi.org/10.1158/00085472.CAN-09-4149

Pieuchot L et al (2018) Curvotaxis directs cell migration through cellscale curvature landscapes. Nat Commun 9:3995. https://doi.org/10. 1038/s41467-018-06494-6

Prager-Khoutorsky M et al (2011) Fibroblast polarization is a matrixrigidity-dependent process controlled by focal adhesion mechanosensing. Nat Cell Biol 13:1457-1465. https://doi.org/10. $1038 /$ ncb 2370

Ranade SS et al (2014) Piezo2 is the major transducer of mechanical forces for touch sensation in mice. Nature 516:121-125. https:// doi.org/10.1038/nature13980

Reid SE et al (2017) Tumor matrix stiffness promotes metastatic cancer cell interaction with the endothelium. EMBO J 36:2373-2389. https://doi.org/10.15252/embj.201694912

Rijal G, Li W (2017) A versatile 3D tissue matrix scaffold system for tumor modeling and drug screening. Sci Adv 3:e1700764. https:// doi.org/10.1126/sciadv. 1700764

Romac JM, Shahid RA, Swain SM, Vigna SR, Liddle RA (2018) Piezo1 is a mechanically activated ion channel and mediates pressure induced pancreatitis. Nat Commun 9:1715. https://doi.org/10.1038/ s41467-018-04194-9

Rosales AM, Anseth KS (2016) The design of reversible hydrogels to capture extracellular matrix dynamics. Nat Rev Mater 1. https://doi. org/10.1038/natrevmats.2015.12

Rothballer A, Schwartz TU, Kutay U (2013) LINCing complex functions at the nuclear envelope: what the molecular architecture of the LINC complex can reveal about its function. Nucleus 4:29-36. https://doi. org/10.4161/nucl.23387

Sander LM (2014) Modeling contact guidance and invasion by cancer cells. Cancer Res 74:4588-4596. https://doi.org/10.1158/00085472.CAN-13-3294

Schwartz MA (2010) Integrins and extracellular matrix in mechanotransduction. Cold Spring Harb Perspect Biol 2:a005066. https://doi.org/10.1101/cshperspect.a005066

Singh SP et al (2015) A synthetic modular approach for modeling the role of the 3D microenvironment in tumor progression. Sci Rep 5:17814. https://doi.org/10.1038/srep17814

Sinkus R, Siegmann K, Xydeas T, Tanter M, Claussen C, Fink M (2007) MR elastography of breast lesions: understanding the solid/liquid duality can improve the specificity of contrast-enhanced MR mammography. Magn Reson Med 58:1135-1144. https://doi.org/10. 1002/mrm.21404

Song S, Eckerle S, Onichtchouk D, Marrs JA, Nitschke R, Driever W (2013) Pou5fl-dependent EGF expression controls E-cadherin endocytosis, cell adhesion, and zebrafish epiboly movements. Dev Cell 24:486-501. https://doi.org/10.1016/j.devcel.2013.01.016

Stroka KM, Wong BS, Shriver M, Phillip JM, Wirtz D, KontrogianniKonstantopoulos A, Konstantopoulos K (2017) Loss of giant obscurins alters breast epithelial cell mechanosensing of matrix stiffness. Oncotarget 8:54004-54020. https://doi.org/10.18632/ oncotarget.10997

Tweedy L, Knecht DA, Mackay GM, Insall RH (2016) Self-generated chemoattractant gradients: attractant depletion extends the range and robustness of chemotaxis. PLoS Biol 14:e1002404. https://doi.org/ 10.1371/journal.pbio.1002404

Vennin C, Murphy KJ, Morton JP, Cox TR, Pajic M, Timpson P (2018) Reshaping the tumor stroma for treatment of pancreatic cancer. Gastroenterology 154:820-838. https://doi.org/10.1053/j.gastro. 2017.11.280

Vietri $\mathrm{M}$ et al (2015) Spastin and ESCRT-III coordinate mitotic spindle disassembly and nuclear envelope sealing. Nature 522:231-235. https://doi.org/10.1038/nature14408

Vig DK, Hamby AE, Wolgemuth CW (2017) Cellular contraction can drive rapid epithelial flows. Biophys J 113:1613-1622. https://doi. org/10.1016/j.bpj.2017.08.004 
Vijayraghavan DS, Davidson LA (2017) Mechanics of neurulation: from classical to current perspectives on the physical mechanics that shape, fold, and form the neural tube. Birth Defects Res 109:153168. https://doi.org/10.1002/bdra.23557

Vogel V, Sheetz M (2006) Local force and geometry sensing regulate cell functions. Nat Rev Mol Cell Biol 7:265-275. https://doi.org/10. $1038 / \mathrm{nrm} 1890$

Wang YL $(2007,2007)$ Flux at focal adhesions: slippage clutch, mechanical gauge, or signal depot. Sci STKE:pe10. https://doi.org/10.1126/ stke.3772007pe10

Wang S, Stoops E, Cp U, Markus B, Reuveny A, Ordan E, Volk T (2018a) Mechanotransduction via the LINC complex regulates DNA replication in myonuclei. J Cell Biol 217:2005-2018. https:// doi.org/10.1083/jcb.201708137

Wang Y et al (2018b) A lever-like transduction pathway for long-distance chemical- and mechano-gating of the mechanosensitive Piezo1 channel. Nat Commun 9:1300. https://doi.org/10.1038/s41467$018-03570-9$

Wei SC et al (2015) Matrix stiffness drives epithelial-mesenchymal transition and tumour metastasis through a TWIST1-G3BP2 mechanotransduction pathway. Nat Cell Biol 17:678-688. https:// doi.org/10.1038/ncb3157

Werner M et al (2017) Surface curvature differentially regulates stem cell migration and differentiation via altered attachment morphology and nuclear deformation. Adv Sci (Weinh) 4:1600347. https://doi.org/ $10.1002 /$ advs. 201600347

Wolf $\mathrm{K}$ et al (2009) Collagen-based cell migration models in vitro and in vivo. Semin Cell Dev Biol 20:931-941. https://doi.org/10.1016/j. semcdb.2009.08.005

Wolf K et al (2013) Physical limits of cell migration: control by ECM space and nuclear deformation and tuning by proteolysis and traction force. J Cell Biol 201:1069-1084. https://doi.org/10.1083/jcb. 201210152

Woo SH et al (2015) Piezo2 is the principal mechanotransduction channel for proprioception. Nat Neurosci 18:1756-1762. https://doi.org/10. $1038 / \mathrm{nn} .4162$
Woroniuk A et al (2018) STEF/TIAM2-mediated Rac1 activity at the nuclear envelope regulates the perinuclear actin cap. Nat Commun 9:2124. https://doi.org/10.1038/s41467-018-04404-4

Xiao W, Tan Y, Li J, Gu C, Li H, Li B, Liao X (2018) Fabrication and characterization of silk microfiber-reinforced methacrylated gelatin hydrogel with turnable properties. J Biomater Sci Polym Ed:1-33. https://doi.org/10.1080/ 09205063.2018.1493022

Yamamoto H et al (2011) Requirement for FBP17 in invadopodia formation by invasive bladder tumor cells. J Urol 185:1930-1938. https:// doi.org/10.1016/j.juro.2010.12.027

Yang B, Lieu ZZ, Wolfenson H, Hameed FM, Bershadsky AD, Sheetz MP (2016) Mechanosensing controlled directly by tyrosine kinases. Nano Lett 16:5951-5961. https://doi.org/10.1021/acs.nanolett. 6b02995

Yang Y et al (2017) Wet-spinning fabrication of shear-patterned alginate hydrogel microfibers and the guidance of cell alignment. Regen Biomater 4:299-307. https://doi.org/10.1093/rb/rbx017

Yang B, Wolfenson H, Nakazawa N, Liu S, Hu J, Sheetz M (2018) Stopping transformed growth with cytoskeletal proteins: turning a devil into an angel bioarxiv. https://doi.org/10.1101/221176

Yeh YC et al (2017) Mechanically dynamic PDMS substrates to investigate changing cell environments. Biomaterials 145:23-32. https:// doi.org/10.1016/j.biomaterials.2017.08.033

$\mathrm{Yu} X$ et al (2012) N-WASP coordinates the delivery and F-actin-mediated capture of MT1-MMP at invasive pseudopods. J Cell Biol 199:527544. https://doi.org/10.1083/jcb.201203025

Zanconato F, Cordenonsi M, Piccolo S (2016) YAP/TAZ at the Roots of Cancer. Cancer Cell 29:783-803. https://doi.org/10.1016/j.ccell. 2016.05.005

Zeng L, Yao Y, Wang DA, Chen X (2014) Effect of microcavitary alginate hydrogel with different pore sizes on chondrocyte culture for cartilage tissue engineering. Mater Sci Eng C Mater Biol Appl 34: 168-175. https://doi.org/10.1016/j.msec.2013.09.003

Zhao Q et al (2018) Structure and mechanogating mechanism of the Piezo1 channel. Nature 554:487-492. https://doi.org/10.1038/ nature 25743 